\title{
Pedagogia Culturalmente Relevante e Fundos de Conhecimento em Aulas de Matemática
}

\author{
Davidson Paulo Azevedo Oliveira ${ }^{1}$ \\ Milton Rosa \\ Marger da Conceição Ventura Viana ${ }^{3}$
}

\begin{abstract}
Resumo: Este artigo tem como objetivo principal apresentar conceitos e teorizações que discutem as influências social, cultural e política na prática pedagógica dos professores, visto que a aquisição do conhecimento matemático, em sala de aula, pode estar relacionada com as experiências socioculturais vividas pelos alunos no ambiente no qual estão inseridos. Nesse sentido, é importante o estudo de teorias educacionais que possam auxiliar os alunos a ter acesso ao conhecimento matemático necessário para reconhecer a importância da própria cultura no desenvolvimento desse saber. Neste trabalho, são apresentados os Fundos de Conhecimento e a Pedagogia Culturalmente Relevante que, além de valorizar os conhecimentos provenientes de contextos culturais distintos, tentam, pedagogicamente, utilizar o background cultural dos alunos para desenvolver atividades curriculares que incluam e problematizem as práticas cotidianas no processo de ensino e aprendizagem em Matemática.
\end{abstract}

Palavras-chave: Pedagogia Culturalmente Relevante; Fundos de Conhecimento; Aulas de Matemática

\section{Culturally Relevant Pedagogy and Funds of Knowledge in Mathematics Classes}

\begin{abstract}
The main objective of this article is to introduce concepts and theories for the discussion regarding social, cultural, and political influences for pedagogical practice of the teachers. The acquisition of mathematical knowledge in classrooms is related to the students'sociocultural experiences in the environment they live, thus, it is important to study educational theories that develop mathematical knowledge in order to help students to recognize the importance of their own culture in the development of this knowledge. In this regard, theories of Culturally Relevant Pedagogy and Funds of Knowledge are presented in this article because they use knowledge

1 Mestre em Educação Matemática (UFOP). Professor do Instituto Federal de Minas Gerais. Câmpus Ouro Preto. E-mail: davidson.oliveira@ifmg.edu.br.

2 Doutor em Educação em Liderança Educacional pela California State University, Sacramento (CSUS). Professor do Centro de Educação Aberta e a Distância (CEAD) da Universidade Federal de Ouro Preto (UFOP). E-mail: milton@cead.ufop.br.

3 Doutora em Ciências Pedagógicas pelo Instituto Central de Ciências Pedagógicas (ICCP) de Cuba. Professora do Centro de Educação Aberta e a Distância (CEAD) da Universidade Federal de Ouro Preto (UFOP). Email: conceicao@cead.ufop.br.
\end{abstract}


originating in different cultural contexts. Thus, these methodological approaches use students' cultural background in order to develop curricular activities that insert and problematize daily practices in the process of teaching and learning mathematics.

Keywords: Culturally Relevant Pedagogy; Funds of Knowledge; Mathematics Classes

\section{Introdução}

As relações da humanidade com o conhecimento matemático e com o contexto cultural, no qual os conteúdos matemáticos foram criados, permitem a compreensão de ideias, procedimentos e conceitos matemáticos envolvidos em alguns questionamentos elaborados pelos alunos (Rosa, 2010). Muitas vezes, esses questionamentos surgem durante as tarefas realizadas no lar e as atividades desenvolvidas no cotidiano.

A valorização dos conhecimentos adquiridos pelos alunos nas atividades realizadas no lar e na comunidade vem sendo estudada pela teoria denominada Fundos de Conhecimento (Moll, Amanti, Neff, \& González, 1992). Porém, para que esses conhecimentos sejam utilizados como ponto de partida para a ação pedagógica da aprendizagem de conteúdos matemáticos, é necessário que as atividades matemáticas curriculares sejam elaboradas de acordo com os princípios da Pedagogia Culturalmente Relevante (Ladson-Billings, 1995a).

Contudo, a disponibilização de estudos na literatura brasileira sobre o relacionamento entre as teorias dos Fundos de Conhecimento e da Pedagogia Culturalmente Relevante ainda é rara, principalmente, em investigações relacionadas com a área de pesquisa em Educação Matemática. Apesar de vários fundamentos apresentados neste estudo teórico se aproximarem de algumas ideias propostas pelo Programa Etnomatemática (D’Ambrosio, 1990), ressaltamos que os pressupostos das teorias aqui apresentadas serão discutidos sob uma perspectiva crítica que traz a questão do conhecimento escolar como um de seus principais objetivos.

Assim, uma das implicações deste artigo teórico para a Educação Matemática pode estar relacionada com a sua pertinência para as pesquisas nesse campo de investigação, pois procura valorizar a cultura dos alunos, ao mesmo tempo em que se preocupa com o aprendizado de novos conhecimentos por meio de perspectivas metodológicas ainda pouco conhecidas no Brasil para o ensino e a aprendizagem dos conteúdos matemáticos. O desvelamento da realidade propicia a utilização do saber sociocultural dos alunos como uma alternativa metodológica que possibilita o desenvolvimento de um ambiente de aprendizagem favorável ao ensino, pois mostra o interesse político e a valorização das minorias com a utilização de propostas pedagógicas diferenciadas.

Embora essa abordagem possa ser uma das várias finalidades de uma educação matemática escolarizada, as teorias apresentadas, neste artigo, podem ser considera- 
das como um ponto de partida para o desenvolvimento de atividades curriculares sustentadas e significadas nas práticas socioculturais, que procura trazer o background cultural dos alunos para a prática pedagógica, desencadeada nas salas de aula. Essa ação pedagógica é realizada com a elaboração de atividades orientadas, motivadas e induzidas a partir do meio sociocultural dos alunos, e, consequentemente, procura refletir sobre os conhecimentos anteriores, que restabelece a Matemática como uma prática natural e espontânea (D’Ambrosio, 1998).

Nesse direcionamento, se uma ideia matemática está relacionada com os fundos de conhecimento dos alunos, então podemos elaborar atividades curriculares com a utilização de conhecimentos desenvolvidos no próprio cotidiano (Moll et al., 1992) e relacioná-las com os conceitos matemáticos acadêmicos por meio da utilização da pedagogia culturalmente relevante (Ladson-Billings, 1995b). Porém, as situações-problema trabalhadas em sala de aula podem estar desvinculadas dos fundos de conhecimento dos alunos, pois, na maioria das vezes, são situações desconectadas do ambiente sociocultural no qual eles estão inseridos. Esse fato pode ressaltar a dificuldade em utilizar esses fundos de conhecimento nas atividades propostas em sala de aula (Azevedo Oliveira, 2012).

Por outro lado, a sala de aula pode ser considerada como um microespaço de um espaço geral da cultura predominante (Fauvel \& Maanen, 2000). Assim, se os aspectos culturais forem utilizados como um veículo para a aprendizagem em Matemática, então existe a necessidade de estarmos atentos para o tipo de veículo pedagógico que será necessário utilizar em sala de aula para atingir esse objetivo (Gay, 2002).

De acordo com esse contexto, um dos principais objetivos deste artigo é ressaltar a potencialidade existente na utilização dos fundos de conhecimento dos alunos para a elaboração de atividades curriculares baseadas em suas experiências cotidianas (Moll et al., 1992). Contudo, para que esse objetivo seja atingido satisfatoriamente, os professores precisam buscar informações sobre os alunos para entender as ideias matemáticas presentes nas atividades e nas tarefas realizadas por eles em seu cotidiano familiar e comunitário (González, Andrade, Civil, \& Moll, 2001).

Então, é de suma importância que novas abordagens pedagógicas sejam utilizadas em sala de aula por meio da elaboração de atividades matemáticas, culturalmente relevantes, que desenvolvam o conhecimento matemático implícito nos fundos de conhecimento dos alunos. Essa abordagem visa facilitar o ensino e a aprendizagem de práticas matemáticas padronizadas (Moll \& Greenberg, 1990). Com a utilização dos fundos de conhecimento e da pedagogia culturalmente relevante é possível elaborar as atividades matemáticas curriculares, como por exemplo, o ensino das funções. 


\section{Fundos de Conhecimento}

A expressão Fundos de Conhecimento ou Funds of Knowledge é de origem antropológica, sendo primeiramente utilizada nos meios acadêmicos por Wolff, em 1967. Ele a definiu como os recursos e os conhecimentos que os familiares necessitam manipular para que possam enfrentar os problemas cotidianos, relacionados com a economia do lar, como, por exemplo, os fundos calóricos, os fundos sociais e os fundos cerimoniais (Hogg, 2011).

A expressão Funds of Knowledge foi traduzida como Fundos de Conhecimento, pois esses fundos se referem às origens do conhecimento, incluindo o matemático, que foi previamente adquirido pelos alunos em ambientes formais e informais de aprendizagem. Por outro lado, outros componentes desses fundos incluem informações com relação ao acesso a instituições de assistência, programas escolares, auxílios legais, rotas de transporte, oportunidades ocupacionais e também aquisição de serviços e mercadorias essenciais (Velez-Ibanez, 1988 citado por Hogg, 2011). Os fundos de conhecimento podem ser considerados como os corpos de conhecimento historicamente acumulados e as habilidades essenciais desenvolvidas para o bom funcionamento dos afazeres domésticos, bem como para o bem-estar familiar (González et al., 2001).

É importante enfatizar que a definição de fundos de conhecimento vem sendo modificada por diversos autores desde que essa discussão foi introduzida por Wolf em 1967. Esse conceito vem sendo ampliado para incluir também os conhecimentos adquiridos e desenvolvidos na comunidade, não se restringindo, portanto, às famílias e ao contexto familiar. Nessa perspectiva, existem diferentes definições para os fundos de conhecimento, pois os pesquisadores e os educadores trabalham com uma diversidade de contextos a serem considerados nas pesquisas (Hogg, 2011).

A imposição de uma limitação para essa definição parece ser inadequada para determinados propósitos e situações investigativas. Há a necessidade de que a definição, que os pesquisadores utilizam, seja articulada e justificada de modo a fundamentar os trabalhos de pesquisa, pois "essa prática permitirá que cada estudo seja claramente localizado no trabalho, auxiliando o desenvolvimento coerente e claro de novos campos do conhecimento" (Hogg, 2011, p. 673).

Os resultados do estudo conduzido por Moll et al. (1992), na fronteira do México com os Estados Unidos, mostram que os fundos de conhecimento são considerados como sendo os conhecimentos acumulados e historicamente transmitidos, no ambiente familiar, de geração em geração. Esses são os conhecimentos necessários para que os membros de uma determinada família possam realizar as suas atividades e as tarefas cotidianas. Portanto, essa definição está restrita ao contexto familiar. 
Neste artigo, ampliamos a definição de Wolff (1967) e Moll et al. (1992) para os fundos de conhecimento, pois consideramos que a aquisição do conhecimento não está restrita apenas ao ambiente familiar do aluno, mas também aquele desencadeado, de maneira formal e informal, na comunidade escolar e em outros ambientes. As salas de aulas são espaços socioculturais, formados por alunos oriundos de diferentes grupos culturais com características peculiares.

O principal objetivo do estudo de Moll et al. (1992) era o desenvolvimento de mudanças pedagógicas para o ensino da Matemática, as quais considerassem alguns aspectos das habilidades e dos conhecimentos encontrados nos afazeres dos componentes da família dos alunos. Para desenvolver o trabalho proposto, houve a realização de uma pesquisa essencialmente qualitativa que combinou com observações etnográficas compostas por entrevistas com questões abertas e fechadas, histórias de vida e estudo de caso, a fim de retratar com precisão o contexto histórico e social das famílias dos alunos.

Com esse levantamento dos dados, foi possível que os pesquisadores conhecessem os alunos em maior profundidade e, assim, aprendessem sobre as atividades e as tarefas cotidianas realizadas pelos seus familiares. Os pesquisadores estudaram as atividades que os pais e os familiares dos alunos realizavam no trabalho e, em casa, em suas obrigações diárias. Essas informações serviram como ponto de partida para que esses pesquisadores elaborassem planos de aula por meio dos quais pudessem providenciar um aprendizado mais prazeroso e com significado para os alunos (Moll et al., 1992). Dessa maneira, foi possível que os professores utilizassem alguns dos fundos de conhecimento dos alunos para que pudessem acessar importantes ideias e procedimentos matemáticos, provenientes das práticas cotidianas realizadas pelos seus familiares, que podem estar congeladas na realização dessas atribuições.

Ressaltamos que os conhecimentos congelados são caracterizados por ideias, conceitos, procedimentos e práticas matemáticas, escondidos no processo da confecção de produtos culturais, como por exemplo, as cestarias e os brinquedos; da construção das casas (Gerdes, 1988) e do desenvolvimento de uma simbologia matemática para facilitar a aplicação de conceitos algébricos. Embora, muitas vezes, não haja um registro histórico-acadêmico sobre a origem desses objetos culturais, os artesãos e os construtores empregam ideias e princípios matemáticos para a confecção ou construção deles (Rosa \& Orey, 2009). Dessa maneira, as tradições matemáticas, presentes nesses objetos, oferecem investigações matemáticas interessantes, que podem auxiliar os alunos a entender a herança cultural que está presente na história da Matemática, bem como os conceitos necessários para a compreensão de conteúdos da Matemática acadêmica. 
A utilização dos fundos de conhecimento dos alunos possui relevância para o ensino e aprendizagem em Matemática, pois esses conhecimentos são específicos, sendo vinculados às atividades cotidianas desempenhadas pelos integrantes de um determinado grupo cultural, que podem ser incorporados nas atividades curriculares de Matemática desenvolvidas em salas de aula (Moll et al., 1992). Porém, para que os professores tenham consciência sobre os fundos de conhecimento, é importante que eles conheçam os alunos com maior profundidade, mantenham contato com as suas famílias, frequentem os mesmos lugares, visitem as suas casas e conheçam a sua comunidade (Rosa, 2010). É relevante que os professores se aventurem nas famílias dos alunos e em suas comunidades, porém, não como professores, tentando transmitir informações educacionais, mas como aprendizes, procurando entender a maneira como os alunos e os seus familiares atribuem sentido às suas vidas cotidianas (González et al., 2001).

Como todas as famílias possuem uma cultura e um conhecimento próprio, amplo, variado e diversificado, é importante que os professores conheçam, compreendam e entendam alguns aspectos dessa cultura para que possam melhor intervir na construção do conhecimento matemático pelos alunos. Assim, essa abordagem "também envolve a análise da história social das famílias, suas origens e desenvolvimento, e mais proeminentemente, a história do trabalho das famílias, que revelam acumulados corpos de conhecimento domésticos” (Moll et al., 1992, p. 133).

É fundamental que os alunos sejam percebidos holisticamente pelos professores, como pertencentes a uma cultura específica e possuidores de conhecimentos próprios (Rosa, 2010). Nesse direcionamento, os professores, ao se familiarizarem com os conhecimentos dos alunos, não os verão como um simples número em sala de aula, mas como parte essencial do ambiente escolar, pois, dessa maneira, conseguem entendê-los profundamente (Azevedo Oliveira, 2012). No entanto, a falta dessa percepção, pode tornar difícil a tarefa de contextualizar e trazer o cotidiano dos alunos para o currículo escolar, pois os professores não dispõem de meios pedagógicos adequados para que, por meio dos conteúdos curriculares, possam entender as dificuldades epistemológicas que foram desenvolvidas pelos alunos em sua trajetória cotidiana e escolar (Rosa, 2010).

Contudo, usualmente, as aulas ministradas estão desvinculadas do contexto sociocultural dos alunos. Como consequência dessa abordagem pedagógica tradicional, os alunos deixam de atuar como protagonistas do processo de ensino e aprendizagem em Matemática, pois em

contraste com as famílias e suas redes sociais, as salas de aula parecem encapsuladas, se não isoladas, do mundo social e dos recursos da comunidade..., os professores raramente utilizam os recursos dos "fundos 
de conhecimento" do mundo da criança fora do contexto da sala de aula. (Moll et al., 1992, p. 134)

Os alunos devem ser ativos nesse processo para que busquem o conhecimento e a representação matemática por meio de sua simbologia (Radford \& Grenier, 1996), pois, em casa, eles não se comportam como personagens passivos de um aprendizado padronizado, como ocorre na escola, lá são participantes ativos na realização das atividades e das tarefas, mediadas pelas relações sociais (Moll et al., 1992). As relações sociais dos alunos com o mundo são fatores de grande importância para o próprio desenvolvimento interacional e intelectual, visto que os

seres humanos e os seus mundos sociais são inseparáveis, pois estão incorporados um no outro. Então, o pensamento humano é irredutível às propriedades individuais. Ao invés disso, está sempre mediado, distribuído entre as pessoas, as definições, os artefatos, as atividades. (González et al., 2001, p. 122)

Todavia, para que esse relacionamento seja deflagrado de uma maneira adequada, cabe aos professores utilizar os fundos de conhecimento dos alunos em suas práticas pedagógicas curriculares. De acordo com esse contexto, para que os professores tenham consciência sobre esses conhecimentos, é importante que os alunos:

elaborem um diário por um dia, uma semana, ou por algum período determinado de como eles e os outros utilizam a Matemática. Os professores, então, coletam essas informações e as utilizam como base para que possam criar contextos para a resolução de problemas e atividades culturalmente relevantes. (Orey \& Rosa, 2008, p. 33)

A partir dessa abordagem pedagógica, o conhecimento que os professores adquirem a respeito do contexto sociocultural dos alunos pode auxiliá-los na preparação e na elaboração das atividades curriculares necessárias para um melhor aproveitamento das aulas de Matemática (Azevedo Oliveira, 2012). A participação dos professores na pesquisa familiar, o conhecimento das experiências cotidianas dos seus alunos favorecem o desenvolvimento de um entendimento sofisticado dessas atividades e podem ser úteis na elaboração de atividades curriculares em sala de aula (Moll et al., 1992).

O entendimento de como as famílias interconectam o meio no qual estão inseridas com os fundos do conhecimento pode ser utilizado para, também, ligar esse conhecimento com as atividades curriculares propostas pelo currículo matemático (Rosa, 2010). Então, conhecer o contexto familiar também é importante para que possamos buscar respostas para questionamentos do tipo: o "que conta como mate- 
mática? Como podemos encontrar matemática nas famílias que são economicamente marginalizadas? Como podemos ajudar os pais e comunidade a se verem como matemáticos ‘fazendo’ matemática na vida diária?” (González et al., 2001, p. 119).

No entanto, a utilização dos fundos de conhecimento dos alunos, nas aulas de Matemática, é uma tarefa desafiadora, pois os professores nem sempre conseguem auxiliá-los a acessar esses fundos e relacioná-los com os conceitos matemáticos aí presentes. Essas dificuldades advêm da quantidade de turmas que os professores possuem, da diversidade cultural presente em sala de aula (Rosa, 2010). Há a necessidade de um aprofundamento teórico em relação à utilização dos fundos de conhecimento no ensino e na aprendizagem em Matemática, pois a transferência linear desse conhecimento para a sala de aula pode ser problemática. Assim, é necessário conduzir "entrevistas familiares para salientar e utilizar as histórias de trabalho que podem ser potencialmente ricas em ideias matemáticas" (González et al., 2001, p. 119).

É imprescindível que se discuta a inserção dos aspectos culturais do cotidiano dos alunos no ensino da Matemática, para que eles possam perceber como a cultura modifica(ou) e influencia(ou) o conhecimento matemático desenvolvido no decorrer da história (Rosa, 2010). No entanto, ressaltamos que não é somente a cultura dos alunos que deve ser considerada no ensino e na aprendizagem em Matemática, mas, também, os seus fundos de conhecimento, que é uma parte específica de sua cultura e difundidos de geração em geração no ambiente familiar (Azevedo Oliveira, 2012).

Todavia para que a abordagem pedagógica seja implantada satisfatoriamente, compete aos professores utilizar, dentre outras, a Teoria da Pedagogia Culturalmente Relevante, baseada na inclusão das referências culturais que os alunos trazem de casa e da comunidade (Howard, 2003), na elaboração das atividades matemáticas propostas em sala de aula.

\section{Pedagogia Culturalmente Relevante}

O termo Pedagogia Culturalmente Relevante foi utilizado por Ladson-Billings (1995a), em estudo realizado a partir de 1989, com os professores de alunos afro-americanos, considerados educadores por excelência. Essa pedagogia enfatiza o fato de os professores utilizarem a cultura e os fundos de conhecimento dos alunos para que o ensino e a aprendizagem em Matemática sejam relevantes, pois tem por objetivo reafirmar a cultura e os conhecimentos que os alunos acumulam na realização das tarefas caseiras e das atividades comunitárias. Essa abordagem visa salientar quão significativos são os conhecimentos prévios e da cultura dos alunos no ensino e na aprendizagem em Matemática e reafirmar o próprio background cultural (Rosa, 2010). 
A pedagogia culturalmente relevante pode ser definida como aquela que utiliza as características culturais, as experiências e as diversas perspectivas étnicas dos alunos para conduzi-los mais efetivamente no processo de ensino e aprendizagem (Gay, 2002). Essa pedagogia, definida como uma pedagogia da oposição, pois é crítica e comprometida com o coletivo, apresenta três proposições para o processo de ensino e aprendizagem: o sucesso acadêmico, a consciência crítica e a competência cultural (Ladson-Billings, 1995a). Esse enquadramento teórico está embasado nessas três proposições que podem ser consideradas como um tripé, para que se evite a concepção de uma hierarquia entre elas, que, na realidade, são igualmente fundamentais (Gandin, Diniz-Pereira, \& Hypolito, 2002).

De acordo com essas proposições, o Sucesso Acadêmico requer que os professores reflitam sobre as próprias práticas pedagógicas, utilizando metodologias de ensino alternativas com o emprego de mecanismos de apoio pedagógico, como, por exemplo, lições diferenciadas, para auxiliar os alunos a experimentar e atingir o sucesso acadêmico (Ladson-Billings, 1995a). Convém salientar que Ladson-Billings (2006) afirma ter se arrependido de utilizar o termo "sucesso acadêmico", pois foi confundido com a atmosfera opressiva dos testes padronizados aplicados nos Estados Unidos. De acordo com essa autora, o termo que melhor se enquadraria para denominar essa proposição seria "student learning" ou "aprendizado do aluno". Porém, para manter a coerência com a denominação empregada inicialmente, Ladson-Billings (2006) continua utilizando o termo "sucesso acadêmico".

A Consciência Crítica pode ser considerada como o componente pedagógico que ressalta a relevância de os professores estarem atentos para que os alunos aprendam os conteúdos ministrados, pois a escola é uma instituição que tem como objetivo auxiliá-los a adquirir os conhecimentos necessários para que possam atuar crítica e reflexivamente na sociedade globalizada. A pedagogia culturalmente relevante não se limita apenas a lhes fornecer o acesso às informações, ela vai além, ela instrumentaliza os alunos para que eles analisem criticamente os conteúdos que aprendem para buscar respostas para as situações-problema que enfrentam cotidianamente (Gandin et al., 2002). Os conhecimentos adquiridos são ferramentas pedagógicas importantes que estão disponíveis para que eles possam discutir criticamente os fenômenos da realidade, desenvolvendo, dessa maneira, a consciência crítica (Rosa, 2010).

Desse modo, os professores auxiliam os alunos a desenvolver uma ampla consciência sociopolítica, a fim de lhes permitir confrontar com competência os conhecimentos adquiridos na escola com as normas que guiam a sociedade e, sobretudo, enfrentar as desigualdades sociais em prol de uma justiça social em favor do coletivo. A consciência sociopolítica permite aos alunos o entendimento de que os estudos realizados na escola têm um objetivo social importante para a transformação da sociedade (Gandin et al., 2002). 
Contudo, pode acontecer de alguns professores não terem desenvolvido, ainda, a sua própria consciência crítica (Ladson-Billings, 2006). Portanto, os professores precisam, primeiramente, acrescer a sua própria consciência crítica em relação à sociedade por meio dos conhecimentos e da vivência que possuem, a fim de ter embasamento suficiente para propor discussões com os alunos, auxiliando-os no desenvolvimento de sua competência cultural.

Assim, a Competência Cultural tem por objetivo a reestruturação da metodologia de ensino tradicional para incluir o background cultural dos alunos como um veículo a ser utilizado para a aprendizagem em Matemática. Essa abordagem tem como foco a eliminação das diferenças culturais entre os alunos em oposição a um ensino estritamente embasado em raízes eurocêntricas e dominantes. A competência cultural é a proposição mais difícil de ser alcançada pelos professores que pretendem desenvolver essa prática pedagógica em sala de aula, pois possui uma variedade ampla de significados (Ladson-Billings, 2006).

A competência cultural dos alunos pode ser realçada por meio da utilização de alguns de seus fundos de conhecimento, que podem ser a base para a discussão das atividades realizadas em sala de aula. É fundamental que os professores reconheçam a si mesmos nos ambientes social e cultural para que possam auxiliar os alunos a se autorreconhecerm nesses ambientes (Howard, 2003).

A Pedagogia Culturalmente Relevante e os Fundos de Conhecimento são teorias desenvolvidas para a afirmação cultural de alunos marginalizados, que pertencem a grupos minoritários étnicos e sociais. Porém, para que os seus objetivos sejam atingidos, é necessário que os alunos pertencentes a esses grupos sejam incluídos nesse modelo de ensino. A pedagogia culturalmente relevante emerge como o resultado da adoção e da implantação dessas três proposições no currículo escolar, não apenas como uma disciplina específica do currículo escolar, mas como um componente didático-pedagógico presente em todas as disciplinas curriculares, incluindo a Matemática. O conteúdo curricular é apenas um dos componentes dessa pedagogia, e a metodologia é o seu aspecto mais importante (Gandin et al., 2002).

Outro aspecto a ser ressaltado, a partir dessa abordagem, é a canalização dos pontos fortes do desempenho escolar dos alunos para a resolução de exercícios e atividades que demandam muita atenção. Essa abordagem visa encorajar os alunos, auxiliando-os e incentivando-os na escolha pessoal do sucesso acadêmico (Ladson-Billings, 2006).

Em contrapartida, para que essa abordagem seja desencadeada satisfatoriamente nas salas de aula, cabe aos professores a missão de providenciar procedimentos metodológicos de ensino alternativos que apoiem os alunos a alcançar o sucesso acadêmico. As atividades pedagógicas devem estar diretamente relacionadas à vida 
dos alunos e às suas experiências (Ladson-Billings, 1995b). A conscientização do ensino culturalmente relevante é o primeiro passo para a construção de uma ponte entre os ambientes escolar, comunitário e do lar.

Para que esse primeiro passo possa ser concretizado, há de se conhecer a realidade dos alunos, os seus fundos de conhecimento e as condições socioeconômicas nas quais estão inseridos. Então, na perspectiva da pedagogia culturalmente relevante, os professores têm um papel fundamental para auxiliar os alunos a se autorreconhecerm para que não se transformem nos modelos impostos pela sociedade contemporânea (Ladson-Billings, 2006). Assim,

postular uma prática pedagógica efetiva é um modelo teórico que não só direciona o sucesso dos alunos, mas também os auxilia a aceitar e reafirmar a própria identidade cultural enquanto desenvolvem perspectivas críticas que desafiam as desigualdades que as escolas (e outras instituições) perpetuam. (Ladson-Billings, 1995a, p. 469)

Para que os professores consigam ter uma atuação significativa em todo esse processo, eles devem, primeiramente, conhecer a si próprios, para depois auxiliar os alunos a reconhecer a própria identidade cultural (Rosa, 2010). A elaboração e a apresentação de atividades baseadas na cultura da qual os alunos são provenientes é uma das maneiras pelas quais os professores podem auxiliar os alunos a se autorreconhecerem.

As ações pedagógicas dos professores são tão ou mais importantes que um currículo multicultural elaborado para a implantação da pedagogia culturalmente relevante (Gay, 2002). No entanto, é necessário que eles sejam capazes de elaborar práticas pedagógicas que tenham relevância e significado para a realidade social e cultural da comunidade escolar (Howard, 2003), utilizando exemplos da realidade dos alunos para que as aulas se tornem contextualizadas e mais dinâmicas (Ladson-Billings, 2006). Isso porque uma das

razões que as crianças experimentam dificuldades nas escolas é que, tradicionalmente, os educadores tentam inserir a cultura na educação ao invés de inserir a educação na cultura. Essa noção é, provavelmente, verdadeira para muitos alunos que não fazem parte da classe média dominante. (Ladson-Billings, 1995b, p. 159).

Os resultados de um estudo feito por Rosa (2010), em nove escolas de segundo grau, em Sacramento, na Califórnia, nos Estados Unidos, corroboram essa ideia e evidenciam que a maioria dos professores dessas escolas públicas não está preocupada em utilizar o background cultural do corpo discente na elaboração de atividades curriculares culturalmente relevantes. 


\section{Integrando os Fundos de Conhecimento e a Pedagogia Culturalmente Relevante}

É de suma importância a utilização de uma prática pedagógica que se apoie nos aspectos culturais do cotidiano dos alunos. Assim, ao observar os alunos em seus ambientes familiar e comunitário, os professores podem incluir esses aspectos na organização do ensino na sala de aula (Ladson-Billings, 1995a). Essa abordagem pedagógica "também envolve a análise da história social dos familiares, suas origens e desenvolvimento e a história do trabalho familiar, que revela corpos acumulados de conhecimento dos familiares" (Moll et al., 1992, p. 133).

Essa abordagem pedagógica somente será desenvolvida satisfatoriamente, se os professores conviverem com os alunos, entrarem em suas casas (Moll et al., 1992). Entretanto, entender profundamente o background cultural de seus alunos para desenvolver uma prática pedagógica relevante não é tarefa fácil (Azevedo Oliveira, 2012). Há várias barreiras que impedem esse processo: falta de tempo, grande quantidade de alunos nas salas de aulas. Um estudo realizado por Azevedo Oliveira (2012) mostra que existem grandes possibilidades de contribuições para o processo de ensino e para o aprendizado de funções, se os professores se pautarem no relacionamento entre as teorias dos Fundos de Conhecimento e da Pedagogia Culturalmente Relevante. Os dados coletados, nesse estudo, foram analisados e interpretados de acordo com a fundamentação teórica estudada e, também, por meio de procedimentos metodológicos do estudo misto e da análise de conteúdos.

Porém, para que essa abordagem seja desencadeada, é necessário que os professores estejam integrados no meio sociocultural dos alunos por meio da elaboração de atividades matemáticas culturalmente relevantes. Nesse ambiente de ensino e de aprendizagem, os professores culturalmente relevantes criam conscientemente interações sociais para auxiliá-los a atingir os três critérios previamente mencionados, o sucesso acadêmico, a competência cultural e a consciência crítica. Rapidamente, os professores mantêm uma relação fluida professor-aluno, demonstram uma conexão com todos os alunos, desenvolvem uma comunidade de aprendizes, encorajam os estudantes a aprenderem colaborativamente e a serem responsáveis uns pelos outros (Ladson-Billings, 1995a, p. 480).

O aprendizado na sala de aula pode ser acentuado quando os professores aprendem mais sobre a vida cotidiana de seus alunos e familiares (González et al., 2001). Por exemplo, é importante que os professores tenham consciência sobre o tipo de emprego que os pais dos alunos têm, as atividades e as tarefas que normalmente desenvolvem em casa. Conhecer alguns aspectos da cultura dos alunos tem implicações diretas para o ensino e para a aprendizagem de conteúdos matemáticos (Rosa, 2010). Portanto, é necessário acessar os fundos de conhecimento dos alunos 
que, sendo parte da sua cultura, podem ser fontes de muitas ideias, procedimentos, conceitos e práticas matemáticas, que podem ser exploradas pelos professores na elaboração das atividades curriculares dessa disciplina (Ladson-Billings, 1995a).

Não basta apenas conhecer a cultura e os conhecimentos prévios dos alunos para que possamos descongelar o conhecimento matemático que possuem. Há que se entender que tipo de conhecimento esses alunos pretendem adquirir para que possam desenvolver as atividades futuras (Rosa \& Orey, 2005b): “é necessário considerar o contexto social, cultural, político e econômico no qual os alunos estão inseridos, em conjunto com as aspirações futuras de cada indivíduo" (Rosa \& Orey, 2005a, p. 132). De posse desse background cultural, os professores têm elementos para preparar aulas que busquem a integração das atividades cotidianas dos alunos com os conteúdos matemáticos trabalhados em sala de aula, permitindo que desenvolvam a consciência crítica por meio da participação em atividades culturalmente relevantes (Rosa, 2010).

Então, é importante que os professores utilizem as tendências pedagógicas para o ensino e para a aprendizagem da Matemática como apoio para as suas ações pedagógicas para que possam auxiliar no desenvolvimento da criticidade dos alunos. Espera-se que salas de aula com professores culturalmente relevantes favoreçam que os alunos se engajem criticamente na resolução dos problemas enfrentados no cotidiano (Ladson-Billings, 1995b). Carece aos professores adotar uma postura culturalmente relevante para que consigam influenciar os alunos a se tornarem reflexivos e questionarem as suas atitudes, para, consequentemente, reconhecerem e avaliarem os seus posicionamentos e preconceitos (Rosa, 2010).

No entanto, para que os professores se tornem culturalmente relevantes, existe a necessidade de que esses profissionais se engajem com

honestidade e reflexão crítica que os desafia a perceber como a posição deles influencia os estudantes de uma maneira positiva ou negativa, pois a reflexão crítica deveria incluir um exame de como a raça, a cultura, e a classe social modelam o pensamento e o aprendizado dos estudantes e os vários entendimentos do mundo. (Howard, 2003, p. 197)

Nessa prática pedagógica, o ensino culturalmente relevante requer que os "professores estejam atentos às necessidades acadêmicas dos alunos, não só fazê-los se sentirem bem. A chave do ensino culturalmente relevante está na escolha do ensino acadêmico por excelência" (Ladson-Billings, 1995b, p. 160). De acordo com esse ponto de vista, essa abordagem pedagógica não é simples de ser alcançada, pois, no ensino culturalmente relevante, existe a necessidade de que os alunos escolham o ensino acadêmico por excelência e permaneçam culturalmente fundamentados 
ao desenvolver competências e habilidades que os auxiliem em sua realização individual e comunitária (Ladson-Billings, 2006).

É importante que esses professores adquiram ferramentas pedagógicas para que possam determinar os pontos forte e fraco de um plano curricular multicultural e, também, dos materiais instrucionais para que possam realizar as mudanças curriculares necessárias, visando à melhoria da qualidade desses instrumentos pedagógicos (Gay, 2002). O currículo multicultural tem de privilegiar os conhecimentos dos participantes da comunidade escolar, principalmente, dos grupos minoritários, para que os interesses de todos estejam representados nas atividades desenvolvidas na escola (Sacristán, 1995).

Cabe aos professores desenvolver repertórios do ensino multicultural que sejam relevantes e compostos por atividades ricas em exemplos cotidianos para serem utilizados no ensino de alunos linguística e etnicamente diversos (Gay, 2002). Todavia, a elaboração desse tipo de atividades curriculares "não é algo que acontece automaticamente ou simplesmente porque queremos, pois é uma habilidade aprendida, que deveria ser ensinada em programas de formação de professores" (p. 113). No contexto da pedagogia culturalmente relevante, o processo de ensino e de aprendizagem começa com o

entendimento do papel dos exemplos no processo de instrução, do conhecimento de culturas e experiências de diferentes grupos étnicos, colhendo exemplos de diferentes fontes críticas e aprendendo como aplicar exemplos multiculturais no ensino de outros conhecimentos e habilidades, como, por exemplo, a utilização de ilustrações de arquiteturas étnicas, padrões de tecidos e receitas no ensino de princípios geométricos, operações matemáticas e pensamento proporcional. (Gay, 2002, p. 113)

A influência de atitudes, valores e comportamentos que os alunos e professores trazem para o processo de ensino e de aprendizagem, deflagrado na escola, são alguns dos principais determinantes para o insucesso escolar dos alunos (Gay, 2002). Dessa maneira, a educação para uma

sociedade multicultural exige o respeito pelos conhecimentos prévios dos alunos, o uso de imagens e representações adequadas ao seu meio e a não imposição de modos de pensar e agir estranhos às suas origens, procurando posturas educacionais que permitam preservar a diversidade e eliminar a desigualdade. (Motta, 2006, p. 63)

Por exemplo, um estudo conduzido por Ladson-Billings (1995a) mostra o caso de um professor participante, inglês, cujos alunos, provenientes de países de língua 
não inglesa, aprendizes desse idioma, precisam executar algumas tarefas. No início do ano, ele os incentivou a utilizar a língua em que se sentissem mais confortáveis - a inglesa ou a materna - para a resolução das atividades propostas. Já no final do ano letivo, os alunos podiam escrever as suas respostas nas duas linguagens utilizadas em sala de aula, a acadêmica e a informal. A autora concluiu então, que o incentivo da escrita na própria linguagem dos alunos e a utilização de símbolos, que criaram, facilitou a compreensão da escrita matemática acadêmica utilizada no ambiente escolar.

Assim, considerando a linguagem algébrica como um idioma ou como um sotaque especial (Rosa \& Orey, 2005b), as estratégias utilizadas pela professora citada por Ladson-Billings (1995a) podem ser empregadas para que os alunos possam utilizar as suas próprias escritas para escrever em palavras e símbolos os conceitos da Matemática, bem como aprender os símbolos matemáticos criados pelos seus colegas. Contudo, é importante que os alunos também sejam encorajados a escrever as suas próprias ideias matemáticas com a utilização da linguagem matemática acadêmica (Rosa \& Orey, 2005b).

Para que uma prática pedagógica seja culturalmente relevante, três objetivos são fundamentais (Howard, 2003):

- Primeiro: aceitar que a noção básica do déficit cultural de alunos diversos continua a permear o pensamento escolar tradicional, como por exemplo, as práticas de ensino e os procedimentos de matrícula. Os professores devem refletir e criticar as suas próprias ações e práticas pedagógicas para assegurar que não haja um reforço de um determinado comportamento preconceituoso.

- Segundo: reconhecer as conexões explícitas entre a cultura e o aprendizado, sendo o capital cultural dos alunos um ativo sociocultural e não um empecilho para atingir o sucesso escolar.

- Terceiro: verificar como as práticas de ensino tradicional refletem, nas classes econômicas inferiores, os valores culturais da Europa e dos Estados Unidos, procurando, então, incorporar uma grande variedade de práticas de ensino dinâmicas e baseadas no cotidiano dos alunos para contradizê-los.

Em nosso ponto de vista, as teorias dos fundos de conhecimento e da pedagogia culturalmente relevante são instrumentos significativos para combater a teoria do déficit cultural, que contribui para a difusão da percepção de que os indivíduos pertencentes às classes marginalizadas possuem uma cultura inferior e as deficiências 
de aprendizagem dos alunos (Bourdieu, 1997) se originam do meio sociocultural. A família e os grupos sociais mais próximos aos alunos são determinantes para o desenvolvimento de atitudes e competências necessárias para o ensino e a aprendizagem, que tem por objetivo retirar os alunos de uma situação de fracasso escolar.

\section{Considerações finais}

A Pedagogia Culturalmente Relevante é uma abordagem metodológica de ensino que procura, a partir da utilização dos fundos de conhecimentos, reafirmar os aspectos culturais do cotidiano dos alunos. Contudo, essa reafirmação cultural por meio da utilização dos fundos de conhecimento não está restrita ao emprego da bagagem cultural, previamente acumulada. É de suma importância utilizar os conhecimentos trazidos de casa, da comunidade e de grupos socioculturais, nos quais os alunos estão inseridos, para ampliar e melhorar os conhecimentos aprendidos no sistema escolar. Há de se entender os alunos, holisticamente, no contexto sociocultural no qual estão inseridos.

É necessário detectar, investigar alguns aspectos dos fundos de conhecimento dos alunos por meio de situações cotidianas presentes nas tarefas realizadas no lar, para, a partir daí, com o emprego dos princípios da pedagogia culturalmente relevante, elaborar as atividades curriculares de Matemática. A escola é um local no qual os alunos buscam o aprendizado de conteúdos e o desenvolvimento de competências que os auxiliem a ser críticos e refletir sobre os problemas que afligem a sociedade contemporânea.

Mais pesquisas e investigações precisam ser desenvolvidas, nessa área de Educação Matemática, para verificar como vendo sendo feita a articulação entre os princípios dos fundos de conhecimento e da pedagogia culturalmente relevante em prol de um ensino do conhecimento matemático mais crítico e reflexivo, em consonância com a sociedade moderna.

\section{Referências}

Azevedo Oliveira, D. P. (2012). Um estudo misto para entender as contribuições de atividades baseadas nos fundos de conhecimento e ancoradas na perspectiva sociocultural da história da matemática para a aprendizagem de funções por meio da pedagogia culturalmente relevante. Dissertação de Mestrado profissional em Educação Matemática, Departamento de Matemática. Ouro Preto, MG: UFOP.

Bourdieu, P. (1997). The forms of capital. In A. H. Halsey, H. Lauder, P. Brown, \& A. S. Wells (Eds.), Education: culture, economy, and society (pp. 40-58). Oxford, England: Oxford University Press.

D’Ambrosio, U. (1990). Etnomatemática. São Paulo, SP: Ática. 
D’Ambrosio, U. (1998). Etnomatemática: arte ou técnica de explicar ou conhecer. São Paulo, SP: Ática.

Fauvel, J., \& Van Maanen, J. (2000). History in mathematics education: the ICMI study. Dordrecht, The Netherlands: Kluwer Academic Publishers.

Gandin, L. A., Diniz-Pereira, J., \& Hypolito, A. M. (2002). Para além de uma educação multicultural: teoria racial crítica, pedagogia culturalmente relevante e formação docente. Entrevista com a professora Gloria Ladson-Billings. Educação E Sociedade, 23(79), 175-293.

Gay, G. (2002). Preparing for culturally responsive teaching. Jounal of Teacher Education, 53(2), 106-116.

Gerdes P. (1988). On culture, geometrical thinking and mathematics education. Educational Studies in Mathematics, 19, 137-162.

González, Z, N., Andrade, R., Civil, M., \& Moll, L. C. (2001). Bridging funds of distributed knowledge: creating zones of practices in mathematics. Journal of Education for students placed at risk, 6(1-2), 115-132.

Hogg, L. (2011). Funds of knowledge: an investigation of coherence within the literature. Teaching and Teacher Education, 27(3), 666-677.

Howard, T. C. (2003). Culturally relevant pedagogy: ingredients for critical teacher reflection. Theory into Practice, 42(3), 195-202.

Ladson-Billings, G. (1995a). Toward a theory of culturally relevant pedagogy. American Educational Research Journal, 32(3), 465-491.

Ladson-Billings, G. (1995b). But that's just good teaching: the case for culturally relevant pedagogy. Theory into Practice, 34(3), 159-165.

Ladson-Billings, G. (2006). Yes, but how do we do it? Practicing culturally relevant pedagogy. In J. Landsman, \& G. Lewis (Orgs.), White teachers/diverse classrooms: a guide to building inclusive schools, promoting high expectations and eliminating racism (pp. 29-41). Herndon, VA: Stylus Publishing.

Moll, L. C., \& Greenberg, J. B. (1990). Creating zones of possibilities: combining social contexts. Cambridge, England, Cambridge University Press.

Moll, L. C., Amanti, C., Neff, D., González, N. (1992). Funds of knowledge for teaching: using a qualitative approach to connect homes and classrooms. Theory into Practice, 31(2), 132-141.

Motta, C. D. V. B. (2006). História da matemática na educação matemática: espelho ou pintura? Dissertação de Mestrado, Faculdade de Educação. São Paulo, SP: USP.

Orey, D. C., \& Rosa, M. (2008). Ethnomathematics and cultural representations: teaching in highly diverse contexts. Acta Scientiae, 10(1), 27-46.

Radford, L. , \& Grenier, M. (1996). Entre les chose, les symboles et les idées... une séquence d'enseignement d'introduction à l'algébre. Revue des Sciences de L'éducation, 22(2), 253-276.

Rosa, M. (2010). The perceptions of high school leaders about English language learners (ELL): the case of mathematics. Tese de Doutorado, College of Education. Sacramento: California State University. Sacramento, CA: CSUS. 
Rosa, M., \& Orey, D. C. (2005a). Las raíces históricas del programa etnomatemáticas. Revista Latinoamericana de Investigacion em Matemática Educativa, 8(3), 363-377.

Rosa, M., \& Orey, D. C. (2005b). Tendências atuais da etnomatemática como um programa: rumo à ação pedagógica. Zetetiké, 13(23), 121-136.

Rosa, M., \& Orey, D. C. (2006). Abordagens atuais do programa etnomatemática: delinenando-se um caminho para a ação pedagógica. BOLEMA, 19(26), 19-48.

Rosa, M., \& Orey, D. C. (2009). Challenges faced by multicultural and multilingual schools in the United States: the case of mathematics. La Salle, 14(1), 29-44.

Sacristán, J. G. (1995). Currículo e diversidade cultural. In T. T. Silva, \& A. F. B. Moreira (Orgs.), Territórios contestados: o currículo e os novos mapas políticos e culturais (pp. 83-113). Petrópolis, RJ: Vozes.

Wolff, K. H. (1966). The sociology of knowledge in the United States. Current Sociology, 15(1), $5-25$.

Recebido em: 03/12/2014

Aprovado em: 06/10/2015 